\title{
Speculations on a Privileged State of Cognitive Dissonance
}

\author{
CONRAD MONTELL
}

\begin{abstract}
What is the meaning of human life, or, for that matter, of the life of any creature? To know an answer to this question means to be religious. You ask: Does it make sense, then, to pose this question? I answer: The man who regards his own life and that of his fellow creatures as meaningless is not merely unhappy but hardly fit for life (Einstein, 1982, p. 11).
\end{abstract}

Across the spectrum of cognitions and behaviors, not only do humans express a yearning to discover meaning in nature - many believe that they have discovered it. In the post-Darwinian world, cognitions of a meaningful universe remain widespread.

The foundation of our cognition rests on the firm ground of our sensory-based experience and that of others whom we trust. We then furnish that basic structure with the movables of belief, selected not only from what we perceive to be experientially true but also from what we imagine, and motivated by our apparent need to add "meaning" to important happenings. We go further with this mentality and add meaning to our understanding of the overall environment, to our own attitudes and emotions, and, as Einstein suggests, to life itself. All religions attempt to fill the human need for meaning, as expressed in believing and belonging (Baumeister, 1991). The strength and importance of our resultant beliefs vary, of course, as the consistency and perceived importance of our behaviors vary, in the two-way relationship of what we know and believe, and what we do. In the happiest of mental states all the beliefs and behaviors would nicely fit together. Some might clash, but as the disharmony began to cause discomfort, it would be resolved; one belief or behavior would move in relation to the other, or both would adjust their position so that internal harmony would be restored.

However, we also have an esteem-seeking and often irrational self to satisfy, a self more concerned with feeling good than with nicely fitting things together. Consider the number of people who consult psychologists and spiritual practitioners to improve their affective states compared to the number of those who 
consult physical and biological scientists to improve their cognition of the world. This esteem-seeking and often irrational self denies and represses, as well as admits and accepts, new cognition. Rank (1978) speaks of a counter-will which not only says, "'I will not perceive what is,' but 'I will that it is otherwise, i.e. just as I want it,'” (p. 39). Humans have the apparent free will to reject some of their natural cognition of events in favor of supernatural explanations.

\section{DEVELOPMENT OF RELIGIOUS COGNITION}

There is much literature on the development of mortality awareness and its impact on religious cognition. In becoming aware of death, we have to deal with that awareness as well as that of the event itself (Becker, 1973; Brown, 1959; Langs, 1996; Langer, 1982, 1972, 1967; Pyszczynski, Greenberg, \& Solomon, 1997). Other animals, whose awareness is imprisoned in present time (Bronowski, 1977), merely suffer death. Humans develop apprehensive fears, and with them the need for some protection from seemingly unavoidable threats or, at least, the need for some protection from potentially debilitating thoughts.

Unlike other animals, we get to know, or to believe we know, more than we sense. Via imagination and symbolic thought, humans develop religious cognition. We get to know (or imagine) something about the future and change. What natural selection for fitness would encompass such a mentality? We know this much. We have evolved with structures that give us the ability to imagine something beyond the sensed environment and beyond the constraints of cause and effect. This ability has its disadvantages. Imagination-based cognition has enabled Homo sapiens to engage in a variety of religious behaviors that, though psychologically beneficial in allowing humans to feel secure while engaging in the precarious activities of making a living, can sometimes be physically harmful and counter-survival. Further, since all of human behavior occurs in the sensed environment, an imagined "environment" with supernatural forces creates an ongoing condition of cognitive inconsistency.

Philosophers and poets address this inconsistency. From a Kantian or a transcendental poet's point of view, there are two worlds: the cause and effect world, the apparent world we experience and get to know, and the world of Godcreated things, each a thing-in-itself with a "reality" that we can never experience or know except by intuition and faith. From such a vantage point, the world of science and that of religion lead to separate cognitions that, though qualitatively different, do not conflict, and thus allow hope for some cognition of God. However, as a practical matter, few people are able to conduct their lives believing in such separate worlds of appearance and reality without suffering the discomfort of cognitive dissonance.

By definition God is supernatural, immortal, having special powers over the course of nature, and hence, able to suspend cause and effect reality, as we get to 
know that reality. There is still much we don't know about causality. For example, our ancestors believed that gods cause rain; our cognition is that of nature. But do we know the specific causality? Consider it in the sentence "It is raining." Notwithstanding our uncertain knowledge, we know, or believe, that it is the effect of natural causes. Yet, many individuals also believe that Yahweh caused the rain and flood described in Genesis.

In Western society the prevailing God is Jesus; over 250,000,000, more than eighty percent of the population of Northern America believe in Jesus and, to varying extents, God's miracles as described in the Bible, including those of creation and resurrection. While that text has remained essentially unchanged in fifteen hundred years, what is known about natural cause and effect has changed greatly in the past 150 years, and with that, I suggest, has come a form of cognitive dissonance, highly resistant to change.

God's laws: the biblical commandments of God, since designed for obedience by mortals, do not involve suspension of natural law. The last six of the commandments form the bedrock of Western morality and law. However, the first four in which God proclaims his supremacy over other gods, and describes his creation of the universe, have increasingly come in conflict with known laws of nature, in the post-Darwinian world.

\section{THE RECORDED POWER OF RELIGIOUS BELIEF}

The laws of causality will not go away, and any individual surviving to selfsufficient maturity must, as a practical matter, acknowledge the cognition that comes with their territory. However, another fact for those researching human cognition and behavior is that widespread belief in a personal God with power over natural events also will not go away. What apparently has changed in the post-Darwinian world is the form and content of religious behavior, and the magnitude of belief in supernatural forces - although there are few data on this. Still, in experiencing conflict and the need to decide between these dissonant cognitions, religious belief often proves to be the stronger. For example, behavior to please God and secure a perceived afterlife often proves to be stronger than "natural" behavior to preserve this known life. Fasting to the point of death, denial of worldly pleasure, human sacrifice, religious inspired suicides and wars, as well as creation of moral codes for the conduct of life, are some of the diverse and continuing forms of such behavior.

Throughout history and continuing into the new millennium, the majority of humans have maintained an unavoidable belief in the laws of causality together with a belief in a god who can replace those laws with a dissonant reward and punishment causality. The biblical God, in an event still widely believed to have occurred, caused the sun to stop in the heavens. Thus, in experiencing "darkness," belief that the sun will soon bring light to the environment may coexist 
with a belief that, with goodness and faith, God will bring light (or has already brought light) to his or her life. Language itself, usage of the reality-forming power of metaphor, facilitates such religious experience (Batson, Schoenrade, and Ventis, 1993). Essentially, there are two types of words: those that have empirical referents and those that do not. Both types appear to be vital in expressing important beliefs (Persinger, 1987).

Belief in natural law with regard to making a living is thus expressible, as well as belief in the efficacy of deities who have the potential to suspend natural law in response to individual prayer. Different from living with dual theories of light as wave and quanta, each for a different aspect of nature and each conforming to the laws of causality, most of humanity has lived with the dissonant cognitions of natural light and God's light, conflicting beliefs used to explain the same aspects of the natural world. Various cognitions of "God's light" motivate a range of religious behaviors, from spiritually inspired acts of kindness and altruism to autos-da-fe and religious wars. To maintain such dissonant cognitions, certain processes of imagination must, somehow, be integrated with those of the external senses. Somewhere in the evolutionary process leading to the human mind and human culture, such integration has occurred, allowing humans to maintain a continuum of beliefs and behaviors from those that are essentially empirically based to those essentially imaginatively based.

\section{THE PREVALENCE OF GURRENT RELIGIOUS BELIEF}

In day-to-day activity humans maintain belief in natural forces (primarily for physical welfare) together with belief in supernatural forces (primarily for "spiritual welfare"). Along that continuum, the belief that life itself has meaning (an idea outside the realm of sensory experience) is, essentially, a religious belief. Benign variants of this belief are maintained by agnostics and those whose belief system centers on cultural and communal meanings of life, subtly giving meaning to and for the lives of mortal individuals whose cultures transcend death (Baumeister, 1991). Most Americans have less subtle forms of religious belief. Most profess belief in a transcendental god and in some form of personal afterlife. As reported (Stark \& Bainbridge, 1985), in the United States, 86\% of the population are sure that "there is life beyond death," (p. 82), "nearly all Americans (96 percent) pray sometimes," (p. 83), with 88 percent saying "my prayers are heard" (p. 85). American youth, notwithstanding all other cognitions, have a belief in a transcendent god. In a nationwide poll conducted by The New York Times and CBS News of over a thousand teenagers, "ninety-four percent say that they believe in God" (Goldstein \& Connelly, 1998). Many people also believe that they sense God's presence on a regular basis (Baumeister, 1991).

Dennett (1985) writes of religions, "they have kept Homo sapiens civilized enough, for long enough, for us to have learned how to reflect more systematically and 
accurately on our position in the universe" (p. 518). However, from the record, the majority of people reflect on our position in the universe in much the same way that they did before Darwin - though, undoubtedly, with more discomfort. Globally, more than five billion of the world's six billion identify as Christian, Muslim, Hindu, or as adherents of some other ancient religion. There is, of course, a rift in human views of "mind," "soul," and individual afterlife. Searle (1997) refers to a largely unspoken-of dichotomy between secular academicians on the one hand, and the rest of the world on the other, between the staunch materialists (monists) and the mass of people (dualists) who feel that mind and soul exist as non-material stuff: "I suppose most people in our civilization accept some kind of dualism. They think they have both a mind and a body. But that is emphatically not the current view among the professionals in philosophy, artificial intelligence, neurobiology, and cognitive science" (p. 43). There are however, "religious" elements within monist belief systems.

In studying dualist beliefs we need more information than is supplied by statistics. We no longer function as in the Dark Ages, when people had little information that conflicted with Genesis and the New Testament, and almost everyone believed that they had a soul and that God was aware of all their daily actions and even their thoughts. Now, our worldviews must at least acknowledge the scientific realities of life as provided by the daily media. Even those who say that they feel God's presence on a regular basis cannot avoid cognition indicating its absence when and where it seems to be needed.

Along with a significant increase in the rate of dissemination of scientific information in the post-Darwinian world there seems to be a significant increase in pseudo-science, New Age religions, and a proliferation of paranormal sensory experiences. It is as if to counter the impact of science on creationism and the concomitant cognitive dissonance, new channels for God and transcendent forces to penetrate the modern world are being created.

Any and all active beliefs that transcendent forces give intrinsic meaning to life come into conflict with an unavoidable awareness of the harsh realities of natural history and current events, rampant human violence and cruelty, as well as natural disaster. Faced with that, one might ask how so many people educated in cause-and-effect reality, whose experience confirms that reality, maintain a belief in the Biblical God of creation, a just God who operates beyond the laws of causality? How can twenty-first century people, with empirical knowledge of recent world events, adhere to a belief in a prayer-answering personal savior without incurring some discomfort? Whether or not such a God functions in some remote part of the universe, the empirical evidence increasingly indicates that no such God functions on earth. How can this seemingly impossible-toavoid logical inconsistency not lead to an impossible-to-maintain psychological inconsistency? Yet, somehow, belief in such a deity is maintained in alert and informed human minds. We have the ability to form and maintain beliefs that ameliorate difficult-to-accept, sensory-based experience and perception. I argue 
that the mind allows these special contra-sensory beliefs to coexist in a privileged state of dissonance. Such beliefs are highly resistant to change and are still widespread, 140 years after Darwin set the stage for modern science and, seemingly, the demise of conflicting religious belief.

\section{ELEMENTS OF THE DISSONANT IMPASSE}

Cognitive dissonance, according to Leon Festinger's (1957) influential theory, is an uncomfortable state of mind that occurs when an individual is confronted with conflicting and seemingly incompatible beliefs and behaviors. Whether or not the incompatibility is "logical," dissonance must be experienced in order for it to cause psychological discomfort. According to current dissonance theory, based on research over the past forty years, when confronted with inconsistent belief and behavior affecting our (mostly positive) sense of self, we are motivated to bring the belief and behavior into some form of compatibility, reduce the dissonance, and avoid information likely to increase it. This motivation is especially strong when the dissonance involves beliefs vital to our self-concept and worldview. Confronted with irrational behavior, one is motivated to eliminate it. According to Festinger, and supported by recent research, such a cognitive discrepancy, in and of itself, is sufficient motivation. There need not be any aversive consequences. Consider our knowledge of gravity; "information that violates the law of gravity would probably arouse dissonance in most persons" (Harmon-Jones, 1999, p. 94). Yet, although increasingly conflicting with experience in the modern world, many individuals still profess belief in such kinds of "information." Dissonance theory fails to account for or explain how these beliefs continue despite the overwhelming presence of contrary cognitions experienced in the post-Darwinian world.

Our quest for empirical knowledge and our belief in it is dictated by our animal need to survive in an experienced physical environment. Our quest for contra-empirical knowledge, especially eschatological knowledge, has, since antiquity, been driven by fear of the elements of nature, and by an apparent human need to countermand certain awesome aspects of the natural order as discovered by our big-brained and curious ancestors (Brown, 1959; Langer, 1982). With knowledge of mortality, "the instinct of knowing and the instinct of living, or rather of surviving, come into conflict" (Unamuno, 1954, p. 114). Even where such conflict has been reduced or eliminated from day-to-day thought, humans, in varying ways and to varying extents, still employ irrational mental processes to find meaning and some imagined form of continuance for individual life, some imagined "pockets of immortality" in which to store life-sustaining beliefs in an assured tomorrow (Montell, 1999). Each of us, I suggest, in forming our worldview, stores the fleeting sensations of important events with recollections and hopes to create an imagined perception of an assured tomorrow. 
These special products of imagination do not undergo the rigid test for believability that is imposed on those of our senses (Ayer, 1952). Religious beliefs operate under a laissez faire policy and are maintained as privileged cognitions, together with empirically based beliefs (Dennett, 1978, 1995). Contrast the continuing belief in biblical creation, post-Darwin, with the changing belief in the earth's shape, post-Magellan. Many people have their heart set on the world as described in Genesis. Few have their heart set on the planet being flat. Sailing the seas, most people want accurate charts. "Sailing through life," many people still prefer Genesis to Darwin's charts.

Culturally established religions usually include dictates of good and sinful behavior: Thou shalt do this; thou shalt not do that. With these come a dissonant cause and effect cognition; obey the gods and be rewarded; disobey and be punished. For most of recorded history, no matter how harsh religion has been, it has proven to be more nurturing to the burgeoning mind than the harshness of indifferent nature. I take as my working definition of religion: "whatever we as individuals do to come to grips personally with the questions that confront us because we are aware that we and others like us are alive and that we will die" (Batson, Schoenrade, \& Ventis, 1993, p. 8). This definition gives us a sense of the dissonant cognitions: empirical awareness of life and death, and denial-of-thatawareness belief and behavior. Based on study of Melanesian and other cultures Malinowski (1954) concludes, "of all sources of religion, the supreme and final crisis of life - death - is of the greatest importance" (p. 47). Terror management theory argues that "the most basic of all human motives is an instinctive desire for continued life, and that all more specific motives are ultimately rooted in this basic evolutionary adaptation" (Pyszczynski, Greenberg, \& Solomon, 1997, p. 1); they are "rooted in the existential dilemma into which our species was born" (p. 2). Contra-empirical religious beliefs emerge from awareness of that dilemma. These beliefs, of course, have served other human needs not addressed here.

\section{ACUTE VERSUS CHRONIC SITUATIONS}

The bulk of cognitive dissonance literature addresses acute situations, such as those involving belief in the prayer-answering power of God, and reports of tragic suffering and death of innocent and pious individuals. These often lead to a strengthening of belief. The belief continues; the event fades from consciousness - although similar events inevitably loom on the horizon. The most salient examples are in the strengthening of religious beliefs occurring in the aftermath of the Holocaust and of subsequent mass murders.

In this paper I suggest that open-ended events and experiences cause a continuing psychological inconsistency. The inconsistency between secular experience in modern society and religious belief is ongoing, marked by many acute situations causing discomfort. Chronic dissonance, I suggest, may be experienced 
as a "background discomfort" similar in certain respects to that felt as a norm of life by sufferers of arthritis and other chronic ailments. Yet, why not alter the beliefs? Why suffer when relief is at hand? Such psychological inconsistencies apparently would not be tolerated in other areas of cognition. What is different about religious belief?

As one approach to an answer, consider the practicality of most human thought in juxtaposition to thoughts about "the human condition." Although awareness of mortality must lurk somewhere in mind, as a practical matter, in most of our day-to-day thoughts and activities, we seem to be only vaguely aware of our impending death. Indeed, one could make strong argument that we are almost completely unaware of it. Our religious beliefs and worldviews are there, kept in place, for those occasional yet crucial times and situations when and where mortality awareness becomes salient and greatly discomforting.

Such discomfort appears to have intensified in the post-Darwinian world, although it varies significantly from individual to individual. Billy Graham, professing to eagerly await death, "so that I can meet Jesus," might be considered as the quintessential example of an individual with a non-discomforting religious cognition. Jimmy Carter, during his successful presidential campaign, reportedly elaborated this religious belief: "I have an assurance of eternal life. There is no feeling on my part that I have to be president, or that I have to live." Although the vast majority of Americans express belief in an afterlife, few seem to manage the existential crisis with a religious cognition that gives anticipatory meaning to death. At the other end of the belief spectrum, we find agnostics and atheists who are dedicated to social movements and intellectual activities and manage the existential crisis quite well, without any belief in a personal afterlife. As Einstein (1982) expressed this: "Neither can I nor would I want to conceive of an individual that survives his physical death; let feeble souls, from fear or absurd egoism, cherish such thoughts," (p. 11). However, we should consider this in relation to Einstein's statement on the meaning of life that begins this paper.

Managing the existential crisis appears to be a continual task of the human mind. The laws of causality, which we come to know from our experience in day-to-day life, are pervasive and encompass all of life. Birth leads to death and disintegration of the individual organism. Yet, the human mind, discovering this hard fact, continues to ask, "Is that all?" In quest of a more favorable answer for human life, the mind finds more evidence for natural causality, but, historically, via imagination, the mind also has found ways of distorting and misinterpreting that evidence and of reinforcing belief in transcendent reward and punishment causality. Although such belief causes a psychological inconsistency that would seem to be the mother of all dissonant cognitions, the most painful, and thus the most in need of resolution, it has continued to defy resolution. I argue that the discomfort is borne by many individuals because the attempt to eliminate or reduce it leads to even more discomfort than that caused by the dissonance itself. Both cognitions appear to be vital to the self, and, thus, both are highly resistant 
to change. This point is crucial to my argument. The laws of causality are valid and psychologically important in daily life. So too, for most of the world's population, is the validity and psychological importance of the laws of God. This duality, this tendency to experience the environment "religiously" as well as naturally, often leads to a cognitive impasse. Along with basic physical survival, all of human cultural history confirms that to survive and flourish psychologically, with awareness of the fragility and finite nature of life, individuals and societies have felt the need to develop some counter-empirical religious belief.

\section{BEHAVIOR AND FAITH}

Contrast faith in God with faith in the trustworthiness of a friend. Faith in a friendship leads to some "bending" of empirical evidence to favor that friend. However, that relationship must meet some test of reality. When a friend acts badly (or fails to act when such action is needed), especially if this recurs, faith in that friend generally will be weakened and eventually destroyed. When God fails to act, this "behavior" is processed in a quite different way. A powerful example of this can be seen in the behavior of orthodox Jews who, sixty years after the Holocaust, continue to pray to a God who, seemingly, allowed the sufferings and deaths of eleven million in death camps, six million of these victims Jews, including infants and the most orthodox of believers. Karen Armstrong (1993), in considering the future of a personal God after the Holocaust writes, "If this God is omnipotent, he could have prevented the Holocaust. If he was unable to stop it, he is impotent and useless; if he could have stopped it and chose not to, he is a monster. Jews are not the only people who believe that the Holocaust put an end to conventional theology" (p. 376). And yet, a significant percent of the world's fourteen million Jews continue to pray to that biblical God, as do an even larger percent of the world's two billion Christians. What stronger evidence is needed for the privileged status of religious belief?

Why this behavior? Billy Graham, in an interview on Larry King's television show, in response to a question about God's "behavior" answered: "I don't know but I'll find out after I die when I meet Jesus." God apparently does not have to meet the same test of reality that friend Jane has to meet.

God cannot behave badly because God does not behave - not in the active sense that everyone else and every object, in conformity to required standards and natural law, behaves. Language allows God that non-active behavior. The word faith, in its basic sense, is reserved for God. There is no process, no action, no verb involved with faith. Distinct even from belief and believing, thought and thinking, trust and trusting, knowledge and knowing, even hope and hoping, there is faith but no "faithing." The original use of faith was "only with reference to religious objects; this is still the prevalent application, and often colours the wider use," (The Compact Edition of the Oxford English Dictionary, 1971). Thus, language 
privileges religious belief. Certain language suggests that human survival requires something more than our daily bread; it suggests that we require something that has been described as "and not by bread alone sustenance." Humans search for such sustenance. We have minds and languages that give that search a special status.

\section{MANAGING THE CHRONIC DISSONANGE IN AGUTE SITUATIONS}

Practical religious behavior such as charitable church activities, rituals, and even certain prayer, in which the petitioner might ask for inspiration and aid in becoming a better person, need not, in and of itself, lead to dissonance and psychological discomfort. In certain practical activities, counter-empirical belief can be rationalized as merely a matter of semantics and of no practical importance. Successful farmers who grow corn or raise sheep for a living will naturally do so in a somewhat scientific way, whether they believe in evolutionary theory or in creationism. Deists will pray for good crops and credit them to God; others will credit luck, human ability and natural circumstances. In certain other activities the dissonant belief may lead to death. Indeed, in the experience of life and death crises and the need to decide between natural and supernatural alternatives, the cognitive dissonance becomes most salient.

A successful farmer who is a Christian Scientist, a believer in faith-healing, may decide to withhold life-saving hospital care to his child, who then dies, the parent then proclaiming: "It was God's will." On the surface, it might seem that this denial of personal responsibility would reduce or eliminate dissonance. Yet, there is much below the surface here. Feelings for such an aversive consequence may shift to more intense feelings for the deity who, as in biblical literature describing Abraham and Job, has tested belief.

There is much in literature and in human studies to advance our understanding of such shifting feelings of responsibility and belief. The believer may justify his or her decision by pointing to similar cases in which an unhospitalized child recovered, and one who was hospitalized died. Whatever the believer's mental discomfort may be, the dissonance remains privileged and, assuming here a male farmer, will not impinge on his scientifically based decisions with corn and sheep. He may also draw comfort from fellow believers. Given a subsequent illness involving another child, he is likely to repeat his behavior in denying hospital care. Beyond the extremity of this belief and behavior with regard to illness are other cognitions that involve magical practice. Faith healers are prevalent on national television, drawing large audiences, with many believers attesting to cures. There is significant evidence of such placebo effects and many religious believers seek magical aid rather than, or in addition to, medical attention. The internet now contains thousands of faith-healing web sites and "chat rooms." The faith-healer's argument: if your faith is strong enough you will be 
healed, falls on the motivated-to-believe ears of individuals ready to suspend disbelief and accept some "gap" in the laws of causality. If healing does not occur, many of those individuals attribute this to insufficiently strong faith. Pentecostal believers around the world now number in the hundreds of millions. They tend to strengthen their beliefs in communal church meetings. Those living in a community of like believers may avoid much of the psychological discomfort of disconfirming cognition pointing to the irrationality of their belief.

Other individuals may maintain dissonant beliefs, even against their better judgment. Mele (1987) gives the example of a student who sincerely states in his philosophy exam that although he is convinced from the evidence that the Christian God does not exist, "he would be unbearably unhappy as an atheist or an agnostic. Such a person believes against his better epistemic judgment but in accordance with his better all-things-considered judgment" (p. 111). Here, with an individual consciously confronting the nature of his belief, an extraordinary cognitive phenomenon is made explicit - the phenomenon of wanting to believe. Rather than a belief naturally selected from what is judged experientially true, the selection is made from all-things-considered judgment - on the basis of what is desired to be true. This individual does not deny his epistemic judgment, he "merely" countermands it to gain the happiness associated with belief in the Christian God. The discomfort of the dissonance is overridden by the happiness of the belief. This individual's candor gives us a peephole into the chronic situation, the continual struggle of variously conditioned individuals in acquiescing to Pascal's wager and in maintaining it despite day-to-day conflicting cognitions.

Similar struggle can be seen in current political and educational conflicts in the United States. As a constant threat to the constitutional separation of church and state, there lurk the mentalities of religiously oriented minds that seek biblical direction for the conduct of life, as well as selective scientific knowledge for survival in the physical world. Consider the action of the Kansas Board of Education in deleting evolution from the state curriculum while professing a belief in science education, (The New York Times, 8/13/99). Evolutionary theory presents a challenge to the privileged dissonance. As one member explains, "there's not meaning in life if we're just animals in a struggle for survival. It creates a sense of purposeless and hopelessness" (p. A13). This mentality is not confined to the land of Oz. It expresses the cognitive dilemma of creationists experienced and educated in a world in which all animals struggle for survival and eventually die, who unyieldingly believe that mankind was created to engage in a spiritual struggle and thus prepare for an eternal life with Jesus. This mentality will yield to science only so far. It will not yield those traditional beliefs that have given purpose and hope to life. The need for purpose and hope appears to be universal and can lead to unexpected dissonance in facing disturbing knowledge that threatens belief in a just and powerful God.

Finding "religious" purpose and hope in life is not limited to discovering God's ways. In the 1957 film, The Bridge on the River Kwai, a British officer in a 
prisoner of war camp becomes obsessed with building a good bridge for the Japanese in order to give purpose and hope to his demoralized fellow prisoners. He does so despite the dissonant cognition of aiding a mortal enemy in ways that might help kill his comrades. This dissonance developed in an extraordinary and temporary situation and required extraordinary but temporary mental effort and imagination. Most dissonant religious belief develops in the conduct of an entire life. The evidence shows that when creative imagination has to work hard to maintain a belief, that belief often strengthens, and actions in support of that belief strengthen. The result of an early experiment testing dissonance theory (Aronson and Mills, 1959) showed that people come to believe and even like (and more strongly believe and like), that for which they suffer.

\section{THE ROLE OF IMAGINATION}

The mind has the ability to distort and diminish anxiety-producing information. Imagination enables Homo sapiens to countermand sensory information, to create images of a more favorable reality, and even to accept fictional worlds with such realities. Imagination enables the various magical practices that permeate our culture, from a benign knocking on wood to ward off evil spirits, to a faith in the healing power of a guru. Magic is often intertwined with religion in the actions of faith healers, who, in placing their hands on afflicted bodies and calling out "heal," act to elicit God's intervention.

Magical practices are found in the form and content of much of what is identified as the paranormal, the occult, and cult movements linked to belief in extraterrestrial life. Expressions of fantasy and the supernatural permeate the media. One need only look at the current movie and television offerings to see the magnitude of this, of how deeply fantasy has been interwoven into the fabric of American life, much of it with some form of supernatural continuance of life. To this volume add the hundreds of thousands of internet websites devoted to the paranormal and the supernatural, many of these websites tied to religious groups and New Age cults. I suggest that this proliferation of fantasy and suspension of disbelief has blurred the lines between the experience of the real world and that of the supernatural. To some extend, this blurring of lines may dampen the experience of dissonance for individuals who spend significant time and energy in these activities. This too is a fertile area for study.

Suspension of Disbelief: "The willingness to withhold questions about truth, accuracy, or probability in a work," (Holman and Harmon, 1992, p. 464), is a term first used by Coleridge to describe what he called "poetic faith." It also applies to religious faith and evidence suggests that throughout history priests and prophets also have been poets. In processing Milton's monumental Christian epic, Paradise Lost, the mind of an agnostic, as well as that of a devout Christian, quite naturally suspends disbelief. There must have been some cause 
and effect evolutionary process leading to such reality-distorting structures and cultural expressions.

In considering phylogenetic processes and cultural change, Lorenz (1977) writes: "If we discover that certain behaviour patterns and norms of social conduct are found in all human beings in all cultures in exactly the same form, we can assume with virtual certainty that they are phylogenetically programmed and genetically specified" (p. 182). While the content of various religions differ, the behavior patterns and norms of seeking meaning and continuity in life, of searching for supersensory powers, and developing belief in such powers, seems to be present in all existing cultures, even those practicing Buddhism (Brown, 1959; Smith, 1958). This behavior existed at the dawn of civilization and, undoubtedly, existed earlier.

d'Aquili and Newberg (1988), based on their neurological research, make the claim that "the brain constructs gods, spirits, demons, or other personalized power sources with whom individuals can deal contractually in order to gain control over a capricious environment" (p. 191). This ability and behavior appears to be in dissonant co-existence with practical animal behavior. d'Aguili and Newberg refer to the neuropsychological mechanisms that underlie religions functioning "to make humans aware of their own mortality and of the contingency of their existence in an unpredictable world. This is the basis of the existential anxiety that all humans bear within them. It is to relieve this curse of cognition, this existential anxiety, that humans first seek mastery over their environment by attempting to organize it mythically and by attempting to control it through the intervention of personalized power constructs" (p. 192). diAguili and Newberg go on to suggest that: "This control aspect of religion, in which the brain generates gods, spirits, and powers and manipulates them by sacrifice, prayer, and other contractual situations, is probably the most primitive form of religion. It is the predominant form in primitive societies. . . present, to some extent at least, even in the most developed and advanced religions. This is certainly true of contemporary popular religious practice" (p. 192).

\section{IMAGINATION IN RELATION TO SENSED REALITY}

Humans do not simply sense and select from the environment. They perceive and filter it in imaginative ways. Unlike the information-seeking external senses, imagination creates its own information: new and sometimes distorted images of the natural world. It is a basic human characteristic, more basic than intelligence, which is abundant in the animal world (Bronowski, 1977). As described here, imagination is an aspect of mind that we know by its lexical meaning: "the act or power of forming mental images of what is not actually present; the act or power of creating mental images of what has never been actually experienced, or of creating new images or ideas by combining previous experiences; creative 
power" (Webster, 1996). It is the "employment of past perceptual experience, revived as images in a present experience at the ideational level" (Drever, 1964, p. 130), "the process of creating objects or events without the benefit of sensory data" (Chaplin, 1985, p. 221).

Stephen (1989) describes certain religious imagination as autonomous imagining, "imagery so compelling, so powerful it can even override all demands of external reality" (p. 56), imagery "experienced as an external, independent reality," which, "is grounded in the psychological reality of a special imaginative process operating outside ordinary awareness" (p. 212). James (1936) describes the power of religious imagination in similar terms.

It is useful here to distinguish between two fundamental mental attributes involved in cognition: intellectual and imaginative. Compared to the intellect, imagination is a more subtle mental phenomenon, seemingly impossible to quantify (Eccles, 1989). "The imaginative process is the human capacity to evoke an image or an idea in the absence of a direct perceptual stimulus" (Rangell, 1988, p. 63), "to make images and move them about inside one's head in new arrangements" (Bronowski, 1977, p. 24). Dennett (1978) speaks of images as existing within a phenomenal space that can contain a god or heaven as well as a tangible object: "Phenomenal space is Mental Image Heaven, but if mental images turn out to be real they can reside quite comfortably in the physical space in our brains, and if they turn out not to be real, they can reside, with Santa Claus, in the logical space of fiction" (p. 186). I suggest that for early Homo sapiens with emerging imagination (as for a large number of modern humans), real objects and "Santa Claus" reside together in some privileged psychological state, despite their cognitive dissonance.

Beres (1960) defines imagination as "the capacity to form a mental representation of an absent object, an affect, a body function, or an instinctual drive. . . a process whose products are images, symbols, fantasies, dreams, ideas, thoughts, and concepts" (p. 327). These individual processes are extended to those of an imitative and thus social nature: to the sharing of illusions and the formation of new images as a social process. Products of imagination are qualitatively different from mere illusions, from that perversion of sensory information, which might occasionally have taken place in pre-imaginative hominid brains (and in those of other animals). With the advent of imagination, illusions would increase and assume new forms and new functions. One positive function would be to divert the individual from fearful thoughts involving "self" and change. Koestler (1964) speaks of this function as "the transfer of attention from the "Now and Here' to the 'Then and There'- that is, to a plane remote from self-interest" (p. 303). In an imaginative state, a mystical state d'Aquili and Newberg (1998) identify as Absolute Unitary Being, individuals lose their sense "of discrete being, and even the difference between self and other is obliterated" (p. 195). Religious literature describes imaginative states in which individuals lose their awareness of self and with it lose their mortal fear. In such states, imagination seems to act 
as a filter or as a screen, distorting, dimming, or obliterating awesome perceptions. In such states, imagination serves to transport or sever the individual from the sources of mortal fear. As Holman and Harmon (1992) describe the historic role of imagination, "it was opposed to reason and regarded as the means for attaining poetical and religious conceptions" (p. 241). Despite the various lexical meanings for something that exists in the imagination as: "fanciful and unreal," I deal with imagination as a real entity. Whatever its physiological nature, it surely is connected to the rest of the neurological structures enabling human cognition. The cognition of God, whether or not with dissonant effects, must, somehow, function in tandem with the rest of an individual's cognition.

\section{SPECULATIONS ON IMAGINATION AND LANGUAGE}

Imagination alters and sometimes removes sensory-generated information and experience from active memory. Humans are sometimes motivated to forget as well as to retain information. Other animals, as an unavoidable consequence of neural change over time, forget, but only humans appear to experience a state of motivated forgetting. Humans have differential recall of pleasant and unpleasant experiences, the ability to eject certain painful experiences from conscious thought, and the ability to repress, or at least dampen, morbid thoughts that have potentially debilitating effects. In recollection, we often bring to mind more or less than what was originally perceived, and, along with practical concerns, anticipations and hopes. As a practical matter, we rarely bring to mind specific thoughts of our own mortality, and never, or almost never, deeply enough so as to imagine our own death. Imagination gives us the ability "to oppose" such awareness and thought.

Language, in turn, as a great departure from calls and gestures, and at a great expenditure of energy, evolved with the capacity to communicate imagined information (Deacon, 1997; Donald, 1991). It is impossible, of course, to transmit religious "information" via calls and gestures. Imagination enabled qualitative changes in the individual. Language enabled qualitative changes in social organization and in human culture. In particular, imagination enabled religious thought and behavior, and language enabled communication of that thought and behavior, in coexistence with thought and behavior based on empirical knowledge. Thus, language itself, essential in communicating religious belief, also has played a vital role in maintaining the cognitive dissonance.

\section{SUMMARY DISGUSSION}

The rules of nature must be obeyed, but so too, for many individuals, must be the rules of God. Render unto Caesar (or nature) the things which are Caesar's 
(or nature's), and unto God the things that are God's. Every god-based cognition has a somewhat different rendering algorithm. Every religious system cuts a somewhat different deal with the natural environment. There is also much that is newly discovered in nature. Although some aspects of the cognitive dissonance I describe are undoubtedly as old as the imaginative search for a more favorable reality, there are aspects that are quite new. The industrial revolution and urbanization in the Western World sped a process of secularism, changed the perceived influence of God in daily events and, increasingly, left uprooted and alienated individuals to fend more for themselves in maintaining their worldview. Following this, it was hardly mere coincidence that the clash of new Darwinianbased knowledge with old creationist religious belief would parallel the proliferation of mental illness (or at least the diagnosis of such).

My speculations on psychological inconsistencies may intersect with others that relate to distortion or misinterpretation of reality, such as denial, repression, self-deception, and that which is sometimes referred to as motivated irrationality. From Spinoza on down, fears of death have been considered, as have fears of other unavoidable bad things, to be irrational. Mele (1987) suggests the need for "a full-scale investigation of the implications of motivated irrational behavior for our understanding of rational behavior" (p. 160). Behind such irrational behavior lie irrational beliefs that raise important questions about knowing. What is the individual's awareness and experience in various situations of the inconsistencies between empirical knowledge and transcendent beliefs?

Human thought is qualitatively different from that of other animals, even when the individuals involved are engaged in similar behavior. Humans constructing a dam to look exactly like a beaver's dam would do so differently, starting conceptually, with symbolical thought of rivers, trees and extraneous matters, qualitatively different from environment-conditioned beaver thought. They would think globally, think of meanings, interject imaginative thought, while constructing at the local river. Yet, it is virtually impossible for a functionally sane, self-sufficient human not to believe in and act from the same laws of nature that drive the beaver. Even those who believe that everything, including all human behavior, emanates from God's commandments cannot but respond to the dictates of the environment via the laws of causality. On a practical basis, one must believe in those laws and behave accordingly. Of course, the psychological inconsistency of this cognition with religious belief would be resolved - if only a just prayer-answering God could be made consonant with a seemingly indifferent and thus "unjust" natural environment. This quest for cognition beyond yet consistent with the natural environment leads to the conception of mystery and to the creation of mythologies. There are neuropsychological data to indicate that "human beings have no choice but to construct myths consisting of personalized power sources to explain their world" (d'Aquili and Newberg, 1998, p. 191). Supporting this, among all people, cultural products reveal the primacy of mortal fears and religious hopes, this in diverse societies throughout time and 
throughout the known world. Every group has had a religion that includes some sense of immortality or some attempt to deny the reality of death (Brown, 1959).

These contradictions in human mentality are difficult to address, much less describe. With all our scientific discoveries and "progress" in understanding the physical world we live in, we have made little progress in understanding the psychological world under our skins. Consider how far we've advanced from Aristotle's and Galileo's knowledge of the physical world, and how little we've advanced from Plato's and Shakespeare's knowledge of human mentality and behavior. The difference here is not merely one of complexity. The essential difference, I argue, is that humans are driven to discover and accept most of nature's secrets - but not all of them. We have come to accept difficult-to-obtain scientific knowledge of the macrocosm and the microcosm, but few have been able to accept the simple empirical knowledge of our animal nature, which includes our death and annihilation. We long ago discovered but have yet to fully accept the simple if awesome facts of human mortality. Viewed as such, this privileged cognitive dissonance should provide fertile ground in the psychological and social sciences for designing explanatory models and for investigating more of that behavior now identified as irrational. Most important, we need to get beyond the laboratory situation, to devise ways of studying chronic dissonance in the daily life of diverse individuals who, despite the seemingly unavoidable discomfort of disconfirming cognition, maintain, or at least profess to maintain, a staunch belief in the biblical God.

\section{Conrad Montell}

105 Commodore Drive

Richmond

CA 94804

USA

E-mail: cmontell@home.com

\section{REFERENCES}

Armstrong, K. (1993). A history of God. New York: Ballantine Books.

Aronson, E., \& Mills, J. (1959). The effect of severity of initiation on liking for a group. Fournal of Abnormal and Social Psychology, 59, 177-181.

Ayer, A.J. (1952). Language, truth and logic. New York: Dover Publications.

Batson, C.D., Schoenrade, P., \& Ventis, W.L. (1993). Religion and the individual: A socialpsychological perspective. New York: Oxford University Press.

Baumeister, R.F. (1991). Meanings of life. New York: The Guilford Press.

Becker, E. (1973). The denial of death. New York: The Free Press.

Beres, D. (1960). Perception, imagination, and reality. The International fournal of Psychoanalysis. 41, 327-34.

Bronowski, J. (1977). A sense of the future. Cambridge MA: The MIT Press.

Brown, N.O. (1959). Life against death: The psychological meaning of history. New York: Vintage Books. 
Ghaplin, J.P. (1985). Dictionary of psychology. New York: Dell Publishing Co.

D'Aquili, E.G., \& Newberg, A.B. (1998). The neuropsychological basis of religion, or why God won't go away. Zygon: Fournal of Religion and Science 33, 187-201.

Deacon, T.W. (1997). The symbolic species: The co-evolution of language and the brain. New York: W.W. Norton and Company.

Dennetr, D.C. (1978). Brainstorms. Cambridge, MA: Bradford Books.

Dennetr, D.C. (1995). Darwin's dangerous idea: Evolution and the meanings of life. New York: Touchstone.

Donald, M. (1991). Origins of the modern mind: Three stages in the evolution of culture and cognition. Cambridge, MA: Harvard University Press.

Drever, J. (1964). A dictionary of psychology. Baltimore: Penguin Books.

Ecales, J.C. (1989). Evolution of the brain: Creation of the self. London: Routledge.

Einstein, A. (1982). Ideas and opinions. New York: Crown Publishers.

Festinger, L. (1957). A theory of cognitive dissonance. Evanston, IL: Row, Peterson.

Goldstein, L., \& Connelly, M. (1998). Teen-age poll finds support for tradition. The New York Times. April 30.

Harmon-Jones, E. (1999). Toward an understanding of the motivation underlying dissonance effects: Is the production of aversive consequences necessary. In E. Harmon-Jones and J. Mills (Eds.), Cognitive dissonance: progress on a pivotal theory in social-psychology (pp. $71-$ 99). Washington: American Psychological Association.

Holman, H.C., \& Harmon, W. (1992). A handbook to literature. New York: Macmillan Publishing Company.

James, W. (1936). The varieties of religious experience. New York: Random House.

Koestler, A. (1964). The act of creation. New York: Dell Publishing.

Langer, S.K. (1967). Mind: An essay on human feeling (I). Baltimore: The Johns Hopkins University Press.

Langer, S.K. (1972). Mind: An essay on human feeling (II). Baltimore: The Johns Hopkins University Press.

Langer, S.K. (1982). Mind: An essay on human feeling (III). Baltimore: The Johns Hopkins University Press.

Langs, R. (1996). The evolution of the emotion-processing mind. London: Karnac Books.

LoRenz, K. (1973). Behind the mirror: A search for a natural history of human knowledge. New York: Harcourt Brace Jovanovich.

Malinowski, B. (1954). Magic, science and religion. Garden City, New York: Doubleday Anchor Books.

Mele, A.R. (1987). Irrationality: An essay on akrasia, self-deception, and self-control. New York: Oxford University Press.

Mrthen, S. (1996). The prehistory of the mind: The cognitive origins of art, religion and science. London: Thames and Hudson.

Montell, G. (1999). Creative imagination: evolutionary theory's recalcitrant problem child. Psychological Inquiry. 10, 342-343.

Persinger, M.A. (1987). Neuropsychological bases of god beliefs. New York: Praeger.

Pyszczynski, T., Greenberg, J., \& Solomon, S. (1997). Why do we need what we need? A terror management perspective on the roots of human social motivation. Psychological Inquiry. 8, 1-20.

Rangell, L. (1988). Roots and Derivatives of Unconscious Fantasy. in Fantasy, myth, and reality. Edited by H.P. Blum, Y. Kramer, A.K. Richards, and A.D. Richards. pp. 6178. Madison, Conn: International University Press.

Rank, O. (1978). Truth and Reality. New York: W.W. Norton \& Company.

Searle, J.R. (1997). Consciousness and the philosophers. The New York Review of Books. 44(4), 43-50. 
Smith, H. (1958). The religions of man. New York: Harper and Row.

Stark, R. \& Bainbridge, W.S. (1985). The future of religion. Berkeley: University of California Press.

Stephen, M. (1989). Self, the sacred other, and autonomous imagination. in The religious imagination in New Guinea. Edited by G. Herdt and M. Stephen. pp. 41-64. New Brunswick: Rutgers University Press.

Stephen, M. (1989). Constructing sacred worlds and autonomous imagining in New Guinea. in The religious imagination in New Guinea. Edited by G. Herdt and M. Stephen. pp. 212-236. New Brunswick: Rutgers University Press.

The Compact Edition of the Oxford English Dictionary. (1971). Oxford: Oxford University Press. Unamuno, M. De. (1954). Tragic sense of life, New York: Dover Publications.

Webster's New World College Dictionary. (1996). New York: Simon and Schuster. 
